\title{
RETHINKING THE ROLE OF RESEARCH PROJECT AS USEFUL METHOD IN GEOGRAPHY TRAINING
}

DOI: http://dx.doi.org/10.18509/GBP.2018.69

UDC: 37:91]:001.891(497.2)

\author{
Dessislava Poleganova \\ Sofia University "St. Kliment Ohridski", Bulgaria
}

\begin{abstract}
Geography didactic faces new challenges related to demand for quality and efficiency of geography training. Contemporary "modern" didactic focuses attention on the development of cognitive abilities of pupils by solving problems and problematic cases; students' stimulation to acquire independently knowledge, skills and competencies; widespread application of problematic and research approach. The topicality of these issues is closely interrelated with the variety of methods applied in geography education. And if we want geography training to be in sync with up-to-date changes in the society and to meet pupils' needs than the role of the research project as a method used in geography training is substantial. The art of conducting and presenting project has its own specifics and offers a lot of opportunities to master the training process and achieve different educational goals. The main aims of the current paper are: to explore and describe in brief the project as geography training method; to present its essence and distinctive features; to define the position of the project in geography training with a view to improve its quality and effectiveness.
\end{abstract}

Keywords: geography, geography didactic, methods of geography training, research project

Geography didactic faces new challenges related to demand for quality and efficiency of geography training. Contemporary "modern" didactic focuses attention on the development of cognitive abilities of pupils by solving problems and problematic cases; students' stimulation to acquire independently knowledge, skills and competencies; widespread application of problematic and research approach. The topicality of these issues is closely interrelated with the variety of methods applied in geography education. And if we want geography training to be in sync with up-to-date changes in the society and to meet pupils' needs than the role of the research project as a method used in geography training is substantial. The art of conducting and presenting project has its own specifics and offers a lot of opportunities to master the training process and achieve different educational goals. The main aims of the current paper are: to explore and describe in brief the project as geography training method; to present its essence and distinctive features; to define the position of the project in geography training with a view to improve its quality and effectiveness.

The research project as method used in geography training is subject to quite a distinctive interpretation in scientific sources. And if we have to assert this we should point out the different notions used very often as synonyms of project - "project training", "project centered training", "project learning", "project work" etc. On the one hand, it proofs its topicality and on the other hand - is a sign for the ambiguous nature of term in theoretical aspect. In the presented paper for the most appropriate definition is accepted the term 
"project" and we define it as a method of the geography training which is part of the socalled "big" methods". [1], [4], [5]

As good working definition in our research is adopted as follows: "Project is synergetic, activity-based, interdisciplinary training activity which leads to solving of real problems... and on the basis of interaction between the pupils, the teacher and other participants...". It is also directed to achievement of particular goal and aims at developing the casual thinking of pupils and social learning in the training process. [1], [2], [3]. This interpretation is the basis for inquiry of essential features and characteristics of project and project training which are subject of interest:

- commitment with pupils' needs/orientation to pupils' interests - the needs and interests of pupils define the choice of project topic and this is a result of their previous experience, current and future way of living.

- social allegiance and the project should be close to reality - the objects of project work in geography training are tasks and problems which arise from the surrounding nature or environment modified by the human society; the economic, cultural and social environment of pupils.

- interdisciplinarity - the project training often cross the borders of thematic subject (geography) and uses information and methods from many other sciences which are needed the stated problem to be solved.

- synergy and taking one's responsibility - pupils organize independently the process of teaching and learning, take part and responsibility in conducting the project and finding the results.

- purposeful planning of project and clear delineation of tasks and problems - the project training is always a deliberate activity and pupils should take decisions about real problems, to plan and organize their own work.

- social learning and team-working - co-work in pupils' groups; cooperative analysis and discussion of problems; sequence of results; mastering the dynamic processes in pupils' groups; equal participation in group work and conducting social learning.

- binding the different pupils' senses - the complex problem could be explored and solved if all pupils' senses are used in active interaction - "how to make mind, heart - and hands work together?".

- conducting a project always led to a final result - a product which is manifested and could be evaluated from the outside/external audience using exhibition, article in newspaper, participation in local television channel etc.

- public and practical significance - project offers possibilities to strengthen the interaction between public activities and school learning when explores problems from every-day life. [1], [2], [4]

Alongside with all above-mentioned advantages the project as "big" method in geography training experiences a number of problems and difficulties when is used:

- problems with re-structuring the curriculum content; the choice of work methods and forms in very restricted timeframes for school teaching; difficult management of goal setting.

- difficulties with the short time which pupils have to process the information and necessity of individual learning of curriculum content.

- problems related to impossibility to conduct standardized control of learning process.

- difficulties with resolution of traditional training tasks which are afterwards subject of objective verification and assessment.

- problems with inequality of less successful pupils. 
- difficulties related to self-organization and planning of teacher's work.

Taking into account the all above-mentioned difficulties and restrictions it is recommended to use the project in coordination with traditional approaches in geography training.

We are searching for proper structure of project training so to become evident the project advantages and in order to increase the effectiveness of geography training. Of course, "hard" structure and well-established way of conducting research project are difficult to suggest because we speak about an open form of training. So having in mind all these notions we present a general and "coarse" structure of implementing project in geography training:

- first stage - initiation/beginning,

- second stage- planning,

- third stage - implementation,

- fourth stage - evaluation,

- fifth stage - application [1].

The teacher gives suggestions, ideas and recommendations about the project that should be elaborated from the pupils at the first stage. These activities could originate not only from the teacher but also from the pupils themselves, the parents and even from outside school participants. It is the most important moment when the teacher should cause pupils' interest about the discussed problems. Other substantial elements being objects of analysis are: importance and topicality of the research project; to make timetables for working process in order to finish in time the project; gathering the needed materials and information; finding the proper facilities for doing the project in school area, etc.

The second stage begins with reconsideration of the whole project, evaluation of topic, harmonization of interactions during the working process, and setting time limits. Only after doing all these we can start with formulation of priorities, aims and particular tasks. The pupils are divided in different working groups, the tasks are distributed amongst them and the important parts of working process are structured. Teacher and pupils discuss the possibilities for mastering the research activities.

The real work is done during the third stage - the implementation of the project. The pupils, divided in groups, are fulfilling specific tasks in logically subordinated steps. This stage is the most dynamic one because then pupils gather, analyze and interpret the information. As intermediate results of the project we can point the solved tasks from divided in small groups pupils.

During the fourth stage - assessment - the different groups of pupils present results of their projects in front of the classmates. The results are discussed, adjusted and supplemented till reaching the final conclusions and formulation. Acting like this helps pupils to practice adequate criteria for assessment which is considerably important for mastering their geography competence.

The last stage - the real application of the project - is very important. The pupils search for possibilities to give publicity of their work (e.g. exhibition, video, slide-show, press release in local radio stations, television or newspapers, etc.). All these actions make pupils efforts visible and they appreciate the real implementation and practical value of school activities in their life and are convinced that it matters.

The geography training offers lots of possibilities for implementing research projects. And this is a fact due to the up-to-date problems and integrative nature of geography science. In projects could be explored topics from different fields of interest - ecology education, intercultural education, problems in contemporary cities, current problems of 
homeland etc. Consequently the geographic research projects should be part of geography curriculum in secondary school. As positive tendency which supports these statements we acknowledge the appearance of such kind of lessons in particular textbooks in geography and economics in Bulgarian schools.

In conclusion we should underline the following final considerations:

- Contemporary "modern" didactic is focused on development of cognitive pupils' abilities through solving problems and problematic tasks; stimulates the independent acquiring of knowledge, skills and competences; uses widely the research and problem-centered approach.

- In order to achieve the above-mentioned aims the role of the research project is very substantial. It is due to its essence and variety of possibilities which it offers.

- Taking into account the possible difficulties and problems related to planning, organization and implementation of research projects it is a must they to be in sync with traditional training methods in geography didactic.

- The nature of geography science implies to put strong stress on implementation of research projects in geography curriculum in secondary schools and its usage in textbooks and the real process of geography training in Bulgarian schools.

\section{REFERENCES}

[1] Василева, М. Методика на обучението по география - едно по-широко разбиране за методите на обучение, УИ „Св. Климент Охридски“, София, 2018

[2] Fridrich, Ch. Projektunterricht und das Fach Geographie und Wirtschaftskunde. Teoretische Grundlagen und Anregungen für die Projektarbeit in der Sekundarstufe I und II., Mat. z. Did. d. Geogr. u. Wirtschaftsk., Bd. 12,Wien, 2000

[3] Pfriem, P. Projekt - In: D. Böhn (Hg.) Did. d. Geogr. Begr. München (Oldenb.), pp. 123-124, 1999

[4] Rinschede, G. Geographiedidaktik. (3.Auflage), UTB Schöningh, Paderborn, Germany, 2007

[5] Vasileva, M. A more comprehensive Understanding of Methods in Geography Training, In: Dimitrovski, R. (Ed.) Knowledge. International Journal Scientific papers Vol. 19.1, Grafoprom Bitola, pp. 285-288, 2017 